\title{
Maximum Power Tracking by VSAS approach for Wind Turbine, Renewable Energy Sources (RES)
}

\author{
Billel Meghni ${ }^{1}$, Nacer Kouider M'Sirdi ${ }^{2}$, Abdallah Saadoun ${ }^{3}$ \\ ${ }^{1}$ Electrical engineering Department, University of Badji Mokhtar, Annaba Algeria and Research Laboratory of \\ Electromechanical systems \\ maghni_1990@yahoo.fr \\ ${ }^{2}$ Aix Marseille Université, CNRS, ENSAM, Université de Toulon, LSIS UMR 7296 LSIS UMR CNRS UMR, Domaine \\ Universitaire St Jérôme, Avenue Escadrille Normandie-Niemen, 13397 Marseille Cedex 20, France \\ nacer.msirdi@Isis.org \\ ${ }^{3}$ Electrical engineering Department, \\ University of Badji \\ Mokhtar, Annaba Algeria and Research Laboratory of \\ Electromechanical Systems \\ Abdallahsaadoun555@gmial.com
}

\begin{abstract}
This paper gives a review of the most efficient algorithms designed to track the maximum power point (MPP) for catching the maximum wind power by a variable speed wind turbine (VSWT). We then design a new maximum power point tracking (MPPT) algorithm, using the Variable Structure Automatic Systems approach (VSAS). The proposed approach leads efficient algorithms as shown in this paper by the analysis and simulations.
\end{abstract} MPPT

Keywords-Wind Turbine; MPP; VSWT; VSAS;

\section{INTRODUCTION}

Wind energy is one of the most promising renewable energy resources for generating electricity due to its cost competitiveness compared to other conventional types of energy resources. Variable speed operation and direct drive Wind Turbines (WT) have been the modern aspect of the Wind Energy Conversion System (WECS) technology Variable-speed has many advantages over fixed-speed [1, 2].

The MPPT algorithms are necessary to maximize, at each time instantly, the produced power is shown in Fig.1. Many MPPT techniques have been proposed as in Figs. [3, 4, 5, 6 and 7]. A lot of them are well established in the literature. They have different aspects and can be classified by: simplicity, convergence speed, digital or analogical implementation, hardware implementation, need for parameterization, sensors required, cost, range of effectiveness, and other aspects. There are several methods: Tip Speed Ratio method (TSR), Sliding Mode Control methods (SMC), Perturbation and Observation method (P\&O), Hill Climbing method, Fuzzy Logic Control method (FLC) and Modified Enhanced (MEPO) among others.

The main objective of this paper is to find the best control for catching the maximum wind power. We then recall the most used techniques and then design a new MPPT algorithm, using the (VSAS) approach to design a robust and efficient algorithm. This approach has been used successfully for PV Systems and can be applied for WTs as shown in this paper [8].

The paper is organized as follows. The problem formulation is given in Section 1. Section 2, presents the mathematical models of the different parts of the considered Wind Energy Conversion System used for simulation. The models of the WT, the Permanent Magnet Synchronous Generator (PMSG) and the converters with connection to the grid are presented. Section 3, presents the most often used MPPT control strategies, for wind turbine driving and then we introduce our new algorithm deduced from the approach considered in [7 ,8]. After its definition, we compare its results with the widely used MPPT algorithms. The fourth section gives some simulation results. Finally, a conclusion summarizes the work and proposes perspectives.

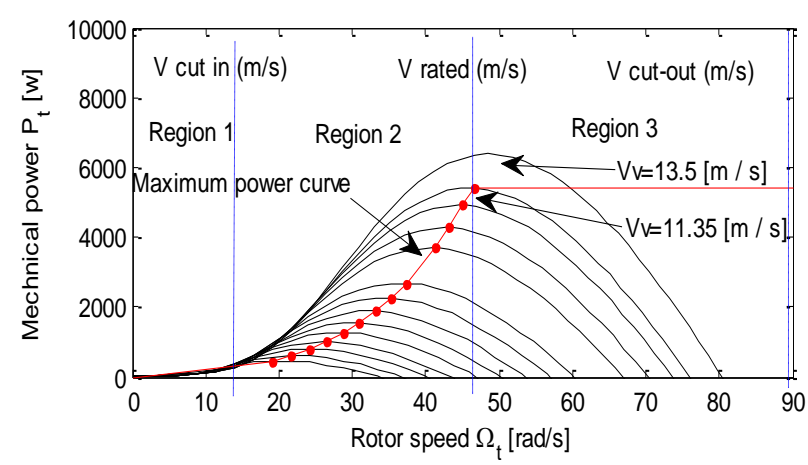

Fig.1.The power characteristic of the considered WT

\section{MODEL OF WIND ENERGY CATCHING SYSTEM}

In order to ensure extraction of the maximal wind energy, it is necessary to use a power electronic device between the WT generator and the grid, 
where the frequency is constant as shown in Fig.2. A WT, a PMSG, AC-DC and DC-AC converters and transformers are to be connected to the grid composing the system. All these parts have to be modeled and simulated.

\section{A. The Wind Turbine model}

The input of the WT is the wind and the output is the mechanical power turning the PMSG rotor [9]. For a VSWT, the output mechanical power can be expressed as:

$P_{\mathrm{t}}=\frac{1}{2} \rho \pi R_{\mathrm{t}}^{2} v^{a} C_{p}\left(\lambda_{s} \beta\right)$

The tip speed ratio is given by:

$$
\begin{aligned}
& \lambda=\frac{R_{\mathrm{t}} \Omega_{\mathrm{t}}}{v} \\
& P_{\mathrm{t}}=K 1 v^{\mathrm{a}} C_{\mathrm{p}}\left(\lambda_{s} \beta\right), \text { Were } K 1=\frac{1}{2} \rho \pi R_{\mathrm{t}}^{2}
\end{aligned}
$$

Where $P_{t}$ in $(w)$ is the output mechanical power available from a wind turbine, $p$ (in $\mathrm{kg} / \mathrm{m}^{\mathrm{a}}$ ) is the air density, $R_{t}$ (in meters) is turbine radius, $v$ (in $\mathrm{m} / \mathrm{s}$ ) is the wind speed, $C_{p}$ is the power coefficient, $\lambda$ is the tip speed ratio, $\beta$ (in degree)is the blade pitch angle and $\Omega_{\mathrm{t}}(\mathrm{in} \mathrm{rad} / \mathrm{s})$ is the rotational speed of the wind turbine shaft.

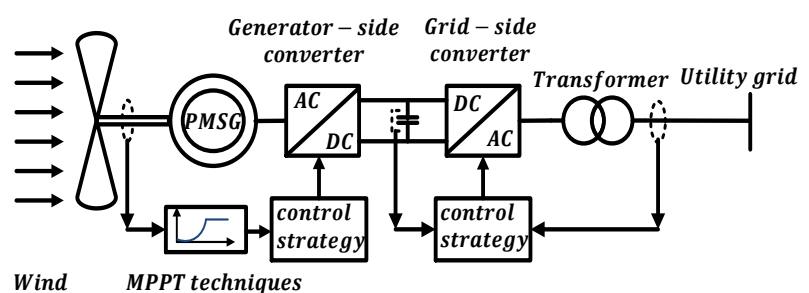

Fig.2. Schematic diagram of the overall system

According to the manufacturer's data of the wind turbine and the curve-fitting technique, the power coefficient $c_{p}$ can be expressed, with $\beta$ the adjustable pitch angle of the blade, as [10].

$$
C_{p}=0.073\left(\frac{151}{\lambda_{i}}-0.058 \beta-0.002 \beta^{2.14}-13.2\right) e^{\frac{-18.4}{\lambda_{i}}}
$$

$$
\text { Where } \quad \lambda_{i}=\frac{1}{\frac{1}{\lambda-0.02,9}-\frac{0.005}{g^{2}+1}}
$$

By using "Equation (4)," the typical $C_{p}$ versus $\lambda$ curve is shown in Fig.3. In a wind turbine, there is an optimum value of $\lambda_{\text {opti }}$ that leads to $C_{\text {pmax }}$. When $\lambda$ in "Equation (2)," is adjusted to its optimal value $\lambda_{\text {opt }}$, the maximum $c_{p}$ is reached when $\beta=0$. The maximum power extraction is achieved. From "Equation (1,2)," we get:

$$
\begin{aligned}
& P_{\mathrm{t} \text { max }}=\frac{1}{2} \rho \pi R_{\mathrm{t}}^{5}\left(\frac{C_{p \max }}{\lambda_{\mathrm{opt}}}\right) \Omega_{\mathrm{topt}}^{\mathrm{a}} \\
& \Omega_{\text {topt }}=\frac{\Delta_{p p t} V}{R_{t}}
\end{aligned}
$$

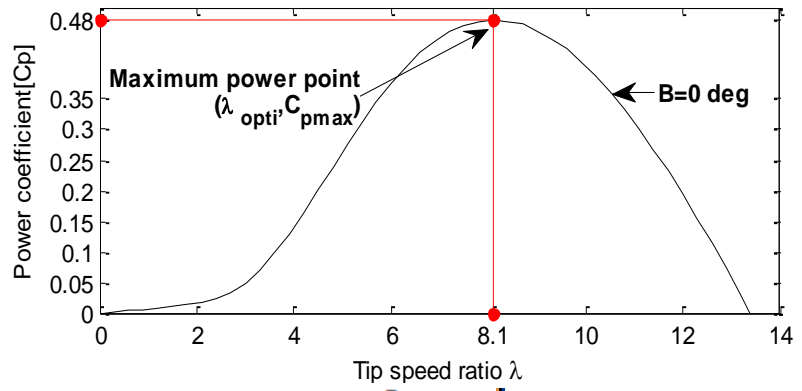

Fig.3.Typical $\mathrm{C}_{\mathrm{p}}$ versus $\lambda$ curve

\section{B. The PMSG model}

The PMSG are usually modeled assuming uniform distribution of stator 3-phase windings. So, a simple model of the generator can be obtained by conversion from the three phases reference frame $a, b, c$ to the $d, q$ frame $[11,12]$.

The model of a three phases PMSG in the $d, q$ reference frame is given by:

$$
\begin{aligned}
& V_{g d}=R_{g} I_{g d}+L_{d d} \frac{d I_{g d}}{d t}-\omega_{g} L_{q} I_{s q} \\
& V_{s q}=R_{g} I_{s q}+L_{q} \frac{d I_{g q}}{d t}+\omega_{\theta}\left(L_{d} I_{g d}+\psi_{m}\right)
\end{aligned}
$$

Where $V_{\mathrm{sd}}, V_{\mathrm{sq}}(\mathrm{in} \mathrm{V})$ are the direct and quadrature components of the PMSG voltages, $\mathrm{R}_{g}, \mathrm{~L}_{\mathrm{d}}$ and $\mathrm{L}_{\mathrm{q}}$ represent respectively the stator winding resistance, the direct and the quadrature inductance of the PMSG stator winding, $\Psi_{\mathrm{m}}$ (in wb) represents the magnet flux, $\omega_{\mathrm{e}}$ (in rad $/ \mathrm{s}$ ) is the electrical rotational speed of PMSG and $I_{s \mathrm{~d}}, \mathrm{I}_{\mathrm{sq}}$ (in A) are respectively the direct and quadrature components of the PMSG currents.

Let $T_{e}\left(i n N_{s} m\right)$ be the electromagnetic torque and $n_{p}$ be the number of pole pairs. The electromagnetic torque developed by a $n_{p}$ machine is given by [11, 12]:

$$
T_{a}=\frac{3}{2} n_{p}\left(\psi_{m} I_{s q}+\left(L_{d d}-L_{q}\right) I_{a d} I_{a q}\right)
$$

\section{The Grid model}

The dynamic model of the grid connection, is referred to the rotating frame synchronized with the grid voltage, this allow us to express the model as: [13].

$$
\begin{aligned}
& V_{d g}=V_{d \mathrm{i}}-R_{g} I_{d g}-L_{d g} \frac{d I_{d g}}{d t}+L_{q g} w_{g} I_{q g} \\
& V_{q g}=V_{q \mathrm{i}}-R_{g} I_{q g}-L_{q g} \frac{d I_{q g}}{d t}-L_{d g} w_{g} I_{d g}
\end{aligned}
$$

Where $V_{\mathrm{dg}}, \mathrm{V}_{\mathrm{qg}}$ (in V) represent the direct and quadrature components of voltages on grid side, while $\mathrm{V}_{\mathrm{di}}, \mathrm{V}_{\mathrm{qi}}$ (in $\mathrm{V}$ ) are the direct and quadrature components of voltages on inverter side, $\left(\mathrm{R}_{\mathrm{g}}, \mathrm{L}_{\mathrm{dg}}\right.$ and $\left.\mathrm{L}_{\mathrm{qg}}\right)$ are resistance, the direct and quadrature grid inductance respectively. The direct and quadrature components of the grid currents are $\mathrm{I}_{\mathrm{dg},} \mathrm{I}_{\mathrm{qg}}$ (in $\left.\mathrm{A}\right)$ respectively. 
By aligning the d-axis of the reference frame along with the grid voltage position, $V_{\mathrm{qg}}=0$, the active and reactive power can be obtained from the following equations:

$$
\begin{gathered}
P_{g}=\frac{a}{2} V_{d g} I_{d g} \\
Q_{g}=\frac{a}{2} V_{d g} I_{q g}
\end{gathered}
$$

Where $\mathrm{P}_{\mathrm{g}}, \mathrm{Q}_{\mathrm{g}}$ are active and reactive grid powers. For simulations of complete WECS chain, the converters, the grid and their connections, Maltlab Simulink programs have been developed and used.

\section{CONTROL TECHNIQUES}

The control technique (MPPT) aims to optimize the generator speed in order to maximize the wind turbine output power. Many strategies were investigated to achieve the MPPT. Three control methods are presented (TSR, SMC, P\&O) and compared to the proposed MEPO algorithm [8].

\section{A. The tip speed ratio control (TSR)}

The TSR MPPT method controls the rotational speed of the generator in order to preserve $\lambda$ to an optimum value at which the power extracted is maximal. This method needs the measure of both the wind and the turbine speed. A speed sensor must be used; this increases its overall system cost. Furthermore, the knowledge of $\lambda_{\text {opti }}$ of the turbine is required. Fig.4, shows the block diagram of a WECS with TSR control [2].

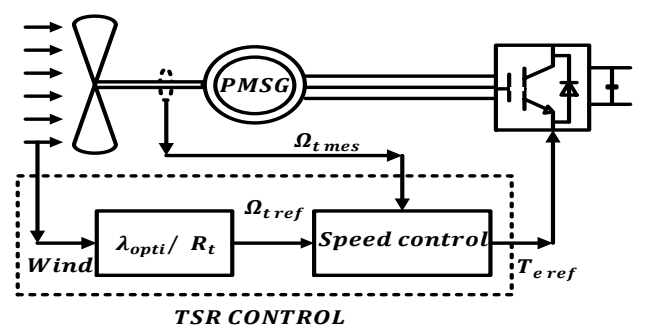

Fig.4.The block diagram of tip speed ratio (TSR) MPPT method

\section{B. The Sliding Mode Control (SMC)}

This part uses a SMC for tracking the optimal power of a variable speed PMSG based WECS as used in [14]. The sliding surface is systematically extracted from imposing a required reduced-order dynamics to enable the WT to work, more or less, close to the optimal regime characteristics. This depends on imposed trade-off between the torque control input ripple and the optimum tracking. In this manner, by torque controlling the PMSG, a multipurpose energy-reliability optimization is actually executed and illustrated in Fig. 5. The two components of the sliding-mode control law are: the equivalent control input $\mathrm{U}_{\mathrm{eq}}$ and the commutation component $\mathrm{U}_{\mathrm{n}}$ that must now be calculated [14].

$$
U_{\theta q}=T_{\theta}-\frac{T_{t}}{\left(1+a_{2} J_{t}\right)}\left(a_{1} J_{t} \Omega_{t}+a_{2} J_{t} T_{\theta}\right)\left(a_{1} A\left(\lambda_{v} v\right)\right)
$$

Where $A(\lambda, v)=\left(\frac{K v R_{t}^{2}}{i^{2}}\right)\left(\frac{C_{p}^{f}(\lambda) \lambda-C_{p}(\lambda)}{\lambda^{2}}\right), k=\frac{1}{2} \rho \pi R_{t}^{2}$

$a_{1}=\frac{-1}{T_{g m}}$

$a_{2}=\frac{-a_{1} \Omega_{\text {totp }}}{T_{e \text { opt }}}$

Where: $T_{s m}$ is a time constant, 1 i is gearbox (drive train) ratio, $\Omega_{\text {totp }}$ is optimal rotational speed of the turbine shaft, $\mathrm{C}_{\mathrm{p}}^{j}(\mathcal{D})$ is the derivative of power coefficient and $\mathrm{T}_{\mathrm{e} \text { opt }}$ is optimal electromagnetic torque.

$$
U_{n}=-\alpha \operatorname{sgn}_{h}(\sigma)
$$

$\mathrm{sgn}_{\mathrm{h}}(\sigma)$ is a hysteretic sign function of width $\mathrm{h}$ and $\alpha$ is the control gain. Finally, the total sliding mode control law is the sum of the equivalent component and on-off component:

$$
U=U_{e q}+U_{n}
$$



Fig.5.The block diagram of the sliding mode control (SMC) MPPT method

\section{The Perturbation and Observation control (P\&O)}

The P\&O method is one of the simplest MPPT techniques as it involves measurement of the power only. It is based on perturbing the speed $\Omega_{t}$ in small step $d \Omega_{\mathrm{t}}$ and perceiving the resulting changes in turbine mechanical power $\mathrm{P}_{\mathrm{t}}$, as illustrated by Fig.6, $[15,5]$. This algorithm is based on the following procedure: if the operating speed of the WT generator is perturbed in a given direction and if the power supplied by the generator increases, it means that the operating point has moved toward the MPP, and therefore the speed of the machine must still be settled in the same direction (see Fig.7). Otherwise, if power operated generator decreases, the operating point is far from the MPP and therefore the direction of the disturbance in the speed of operation must be reversed see eg [12, 13].

Additionally, selecting an appropriate step size is not a simple task: though larger step-size means a faster response and more oscillations around the peak point, and hence, less efficiency, a smaller step-size improves efficiency but decreases the convergence speed $[5,16]$ as represented in Fig.7 and compared to the MEPO and the TSR methods. 


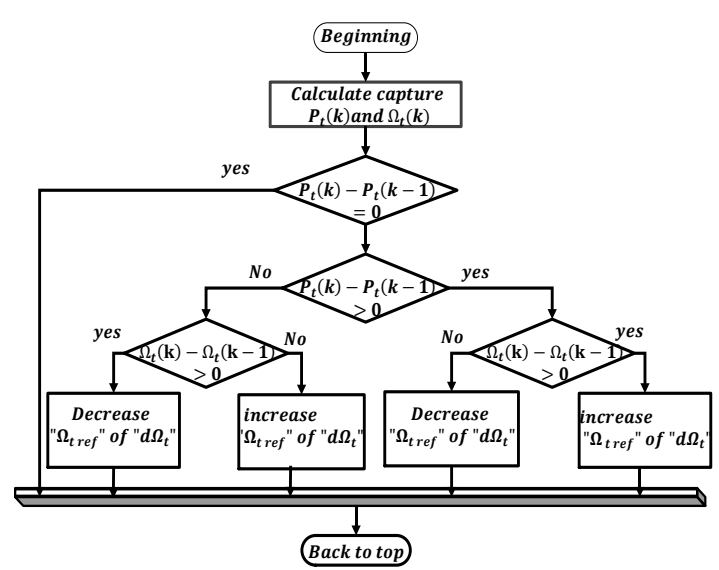

Fig.6. Flowchart of the perturbation and observation (P\&O) MPPT method


Fig.7. Size of $\Delta n_{a}$ perturbation,(a) a larger step-size,(b) a smaller step-size

\section{The Modified Enhanced P\&O Algorithm (MEP\&O)}

For fast and good converging algorithms, the Operation Point moves essentially on a wind dependant characteristic. The change of wind velocity forces it to change from one characteristic curve to another, generally more or less near the new optimum. The maximum Power depends on the WT rotation speed $\Omega_{\mathrm{t}}$ and time: $P_{\mathrm{t}}(\mathrm{t})=P_{\mathrm{t}}\left(\Omega_{\mathrm{t}}(\mathrm{t})\right)$.

Then the required Maximum Power Point to Track is really defined by the following objective function:

$\frac{d P_{t}(t)}{d t}=0$ or $\frac{d P_{t}(t)}{d t}=\frac{d P_{t}}{d n_{t}} \cdot \frac{d \Omega_{t}}{d t}=0$

We can define as Lyapunov function the positive function $W(t)$ where we use a positive constant $P_{0}>P_{t}$ greater than the maximum power which can be got by the WT. W is always positive.

$$
W(t)=\left(P_{0}-P_{\mathrm{t}}(\mathrm{t})\right)^{2}>0
$$

Its time derivative $\frac{\mathrm{d} W(\mathrm{t})}{\mathrm{dt}}$ must be negative to make $W(t)$ always decreasing and then convergence of the algorithm.

$$
\frac{d W(t)}{d t}=-\frac{d P_{t}(t)}{d t}\left(P_{0}-P_{t}(\mathrm{t})\right)<0
$$

Then, to verify this condition, $\frac{d \mathrm{P}_{\mathrm{t}}(\mathrm{t})}{\mathrm{dt}}>0$ must be positive. Let us now consider the control in case of discrete time, like do all the above-presented algorithms. We can estimate the Power derivative $\frac{d P_{t}(t)}{d t}=\frac{d P_{t}}{d \Omega_{t}} \cdot \frac{d \Omega_{t}}{d t}$ by:

$$
\left(P\left(\Omega_{\mathrm{t}}+\Delta \Omega_{\mathrm{t}}\right)-P\left(\Omega_{\mathrm{t}}\right)\right) \cdot \Delta \Omega_{\mathrm{t}}=\Delta P \cdot \Delta \Omega_{\mathrm{t}}>0
$$

Then we choose for the rotational speed perturbation $\Delta \Omega_{\mathrm{t}}=\mathrm{K} \cdot \operatorname{sign}\left(\Delta \mathrm{P} \cdot \Delta \Omega_{\mathrm{t}}\right)$

The fetched MPPT may be defined, in the MEPO algorithm by the following: $\Delta \Omega_{\mathrm{t}}=\operatorname{Ksign}\left(\Delta \mathrm{P}, \Delta \Omega_{\mathrm{t}}\right)$

In case of no change in the output power after perturbation: $\Delta \mathrm{P}_{\mathrm{t}}(\mathrm{k})=0$, then as

In case of $\Delta \mathrm{P}_{\mathrm{t}}(\mathrm{k}) \geq 0$, the power increase after positive perturbation delta $w$ then let us continue in the same direction .

In case of $\Delta \mathrm{P}_{\mathrm{t}}(\mathrm{k}) \leq 0$, the power decreases after positive perturbation delta $w$ then let us continue in the reverse direction. Finally for the rotation speed control we get the following control law:

$$
\Omega_{\text {tref }}=\Omega_{\mathrm{t}}+K \operatorname{sign}\left(\Delta P . \Delta \Omega_{\mathrm{t}}\right) \text { with } k=1
$$

\section{SIMULATION RESULTS AND DISCUSSION}

The simulation has been carried out using Matlab Simulink package, under a wind speed profile whose mean value is $(11.5 \mathrm{~m} / \mathrm{s})$. The evaluation tests have been done with the wind speed input defined by Fig.8, got from a Matlab Simulation. The system parameters are given in the appendix $\mathrm{A}$.

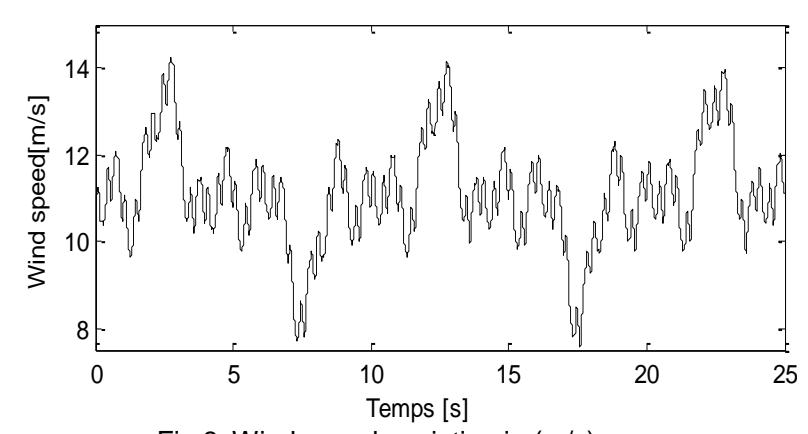

Fig.8. Wind speed variation in $(\mathrm{m} / \mathrm{s})$

The $\mathrm{C}_{\mathrm{p}}$ and the output power is shown in the following for each one of the presented algorithms. The studied and proposed algorithm MEPO based on VSAS approach is tested in simulation and compared with the different MPPT methods (TSR, SMC, P\&O ) are shown in Figs $(9,10,11,12$ and 13); The simulation results are summarized in Table I [2]. 


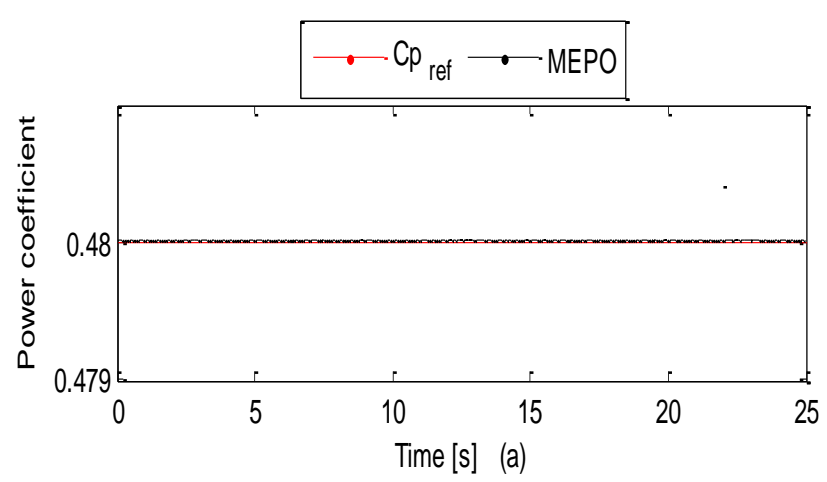

difference. In contrast with MEPO, the classical P \& $\mathrm{O}$ for $(\mathbf{x = 5})$ and SMC methods of are very slow.

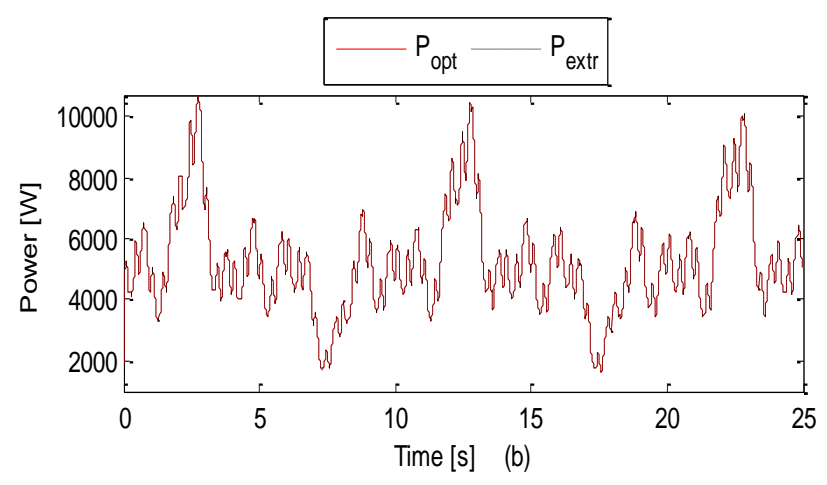

Fig.9. (a) $\mathrm{C}_{\mathrm{p}}$ and (b)optimal and extracted power For [MEPO MPPT]
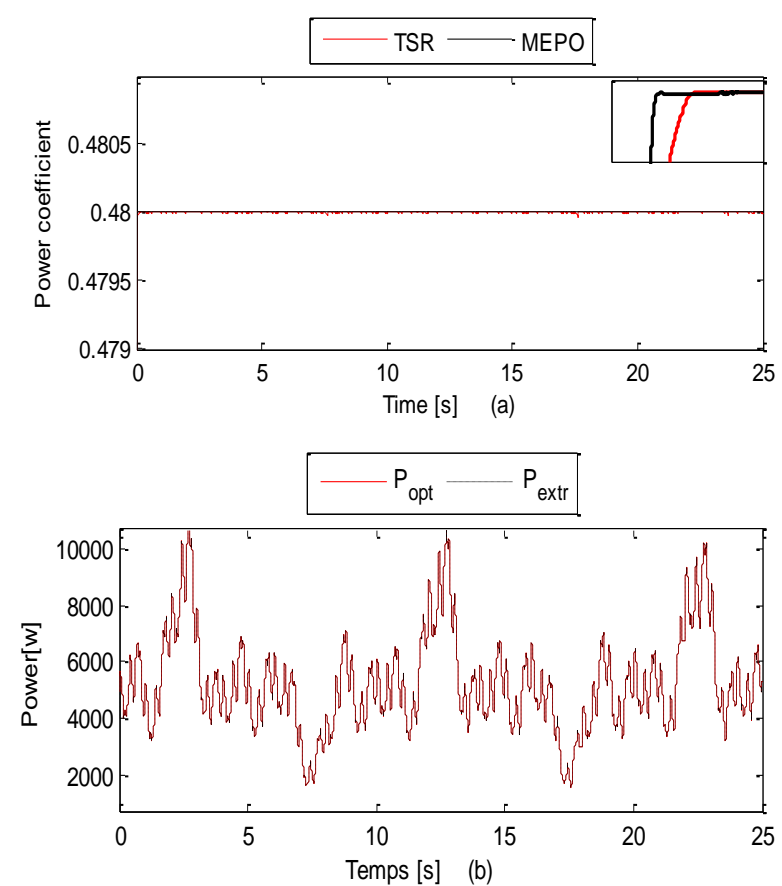

Fig.10. (a) $C_{D}$ and (b)optimal and extracted power For [TSR MPPT]

The MPPT controller ensures the tracking of the optimum power points at variable wind speeds, by maintaining the power coefficient to its maximum value $\mathrm{C}_{\mathrm{p} \max }=0.48$ as shown in Fig.9 (a). Based on the results demonstrated in Figs (9(a), 10(a), 11(a), 12 (a), 13(a))the MEP\&O method were found to be the fastest to reach the steady-state, This shows the effectiveness of the proposed algorithms. While the other algorithms exhibiting a slight
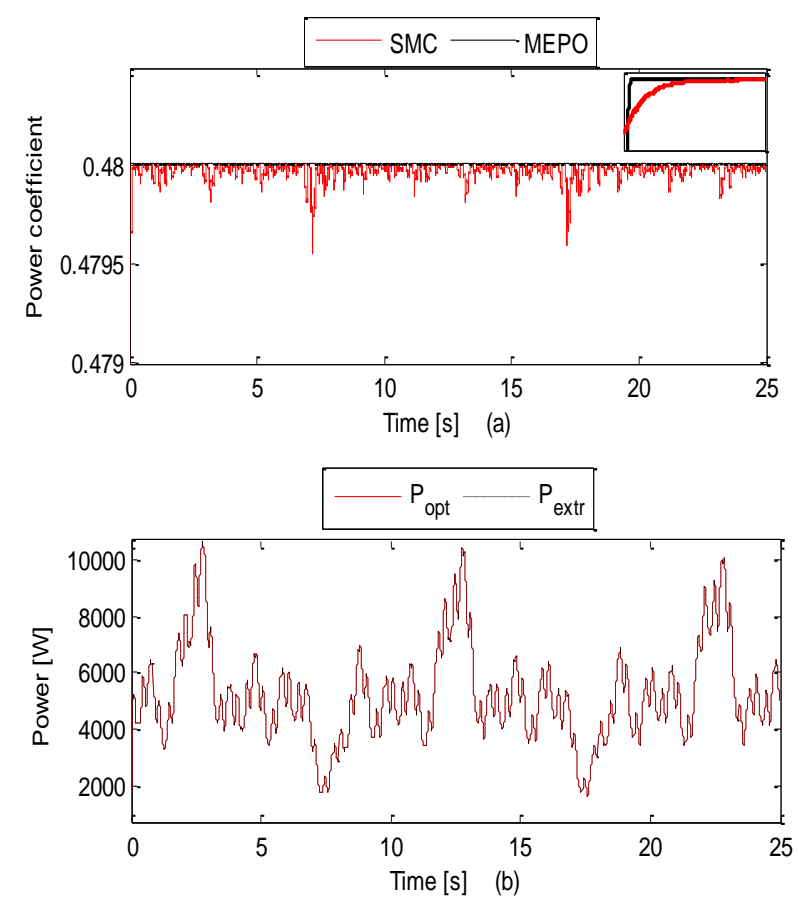

Fig.11. (a) $C_{p}$ and (b)optimal and extracted power For [SMC
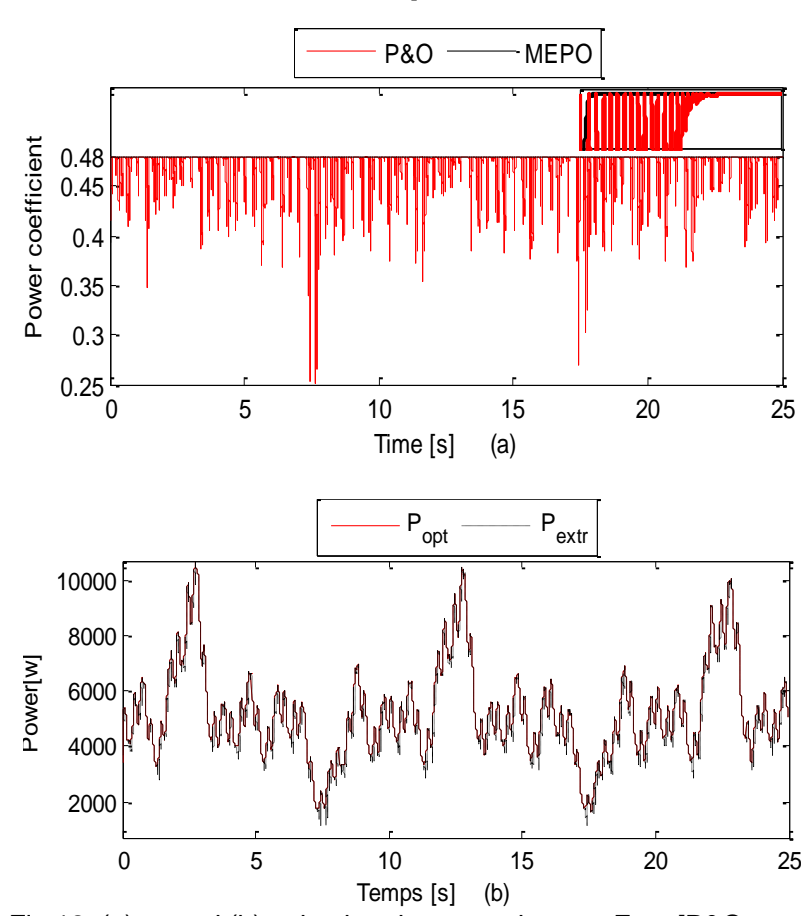

Fig.12. (a) $C_{\mathrm{p}}$ and (b)optimal and extracted power For $[\mathrm{P} \& \mathrm{O}$ MPPT, $\mathbf{x}=5$ ]

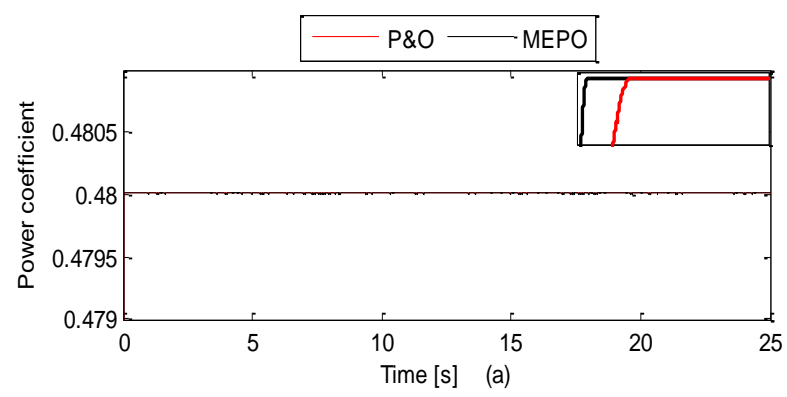




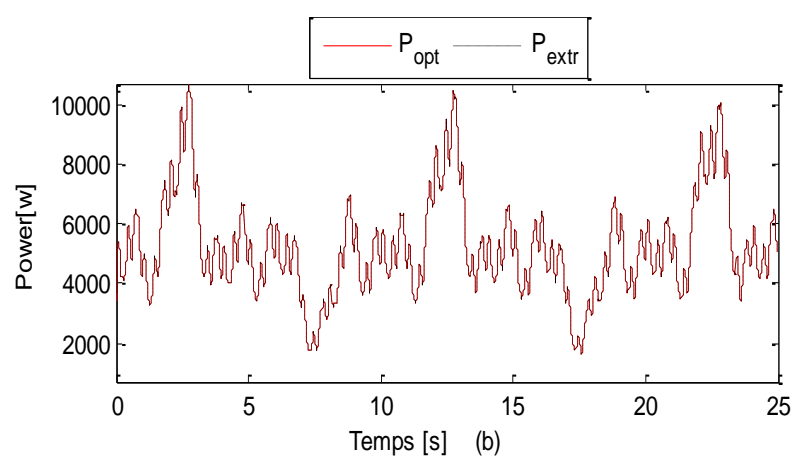

Fig.13. (a) $C_{\mathrm{w}}$ and (b)optimal and extracted power For [P\&O MPPT, $\mathbf{x}=\mathbf{0 . 1}]$

The control algorithm based on MEPO and TSR achieve the highest average value of $\mathrm{C}_{\mathrm{p} \max }$ to an approximate value of 0.480 . By comparison, the SMC gives an average value of $C_{p \max }=0.4794$, which is approximately equal to the $C_{p \max }$ value obtained from the $\mathrm{P} \& O$ for $(\mathbf{x}=\mathbf{0 . 1})$ control. Since the average value of $C_{p \max }$ of the classical $P \& O$ for $(x=5)$ method is 0.4780 , this method is the least effective.

Table 1 .Summary of performance of four algorithms

\begin{tabular}{|c|c|c|c|c|c|c|}
\hline $\begin{array}{c}\text { MPPT } \\
\text { technique }\end{array}$ & $\begin{array}{c}\text { Average } \\
\text { power } \\
\text { Pt kw }\end{array}$ & $\begin{array}{c}\text { Losing } \\
\text { power Pt } \\
\text { (w) }\end{array}$ & $\begin{array}{c}\text { Power } \\
\text { coefficie } \\
n t\end{array}$ & $\begin{array}{c}\text { Tip speed } \\
\text { ratio }\end{array}$ & $\begin{array}{c}\text { Response } \\
\text { time (s) }\end{array}$ & $\begin{array}{c}\text { Efficiency } \\
\text { (Pt/Popt) } \\
\%\end{array}$ \\
\hline TSR & 2.2628 & 0.0211 & 0.4800 & 8.0994 & 0.0295 & $\cong 1_{00}$ \\
\hline SMC & 2.2489 & 2.5941 & 0.4794 & 8.1044 & 0.4982 & 99.87 \\
\hline $\begin{array}{l}P \& O \\
X=0.1\end{array}$ & 2.2598 & 0.1982 & 0.4794 & 8.0983 & 0.215 & 99.97 \\
\hline $\begin{array}{l}P \& O \\
X=5\end{array}$ & 2.2463 & 7.4252 & 0.4780 & 8.1233 & 0.0405 & 99.57 \\
\hline MEP\&O & 2.2613 & 0.0877 & 0.4800 & 8.0992 & $\overline{0.01}$ & $=100$ \\
\hline
\end{tabular}

The verification of maximum power tracking control is illustrated in Figs (9(b), 10(b), 11(c), 12 (b) and 13(b)). The wind speed profiles of maximum power tracking control $P_{\text {opt }}$ is also shown in Figs (9(b), 10(b), 11(b), 12 (b) and 13(b)). From the figures, it has been found that, in the four methods (TSR, SMC, FLC, P\&O), the extracted power by the turbine follow the desired trajectory $P_{\text {opt }}$ with different efficiency; the calculated efficiencies are listed in Table I.

\section{CONCLUSION}

In this paper we present the models of the different parts of a Wind Energy Conversion System: the WT, the PMSG, and the converters with connection to the grid are presented. The most often used MPPT control strategies are reviewed, for wind turbine driving and then we propose a new MEPO algorithm deduced from the VSAS approach. We compare our algorithm with the widely used MPPT algorithms.

The verification of maximum power tracking control is illustrated in the presented figures show that the best MPPT algorithm is the MEPO. The wind speed profiles of maximum power tracking control $\mathrm{P}_{\mathrm{opt}}$ and the dynamic difference between the turbine powers $P_{t}$ is also shown. From the figures, it has been found that, in the four methods (MEPO, TSR, SMC, P\&O), the extracted power by the turbine follow the desired trajectory $\mathrm{P}_{\text {opt }}$ with different efficiency; the calculated efficiencies are listed in Table III. As perspective, we will focus on the control and stabilization for the grid connection of multiple sources and Hybrid Renewable Energy Systems by using again VSAS like used in MEPO.

\section{APPENDIX A}

Table 1. Wind turbine Parameters

\begin{tabular}{|l|l|}
\hline Radius of the turbine & $\mathrm{R}_{\mathrm{t}}=2 \mathrm{~m}$ \\
\hline Volume density of the air & $\mathrm{p}=1.225 \mathrm{~kg} \mathrm{~m}^{\mathrm{z}}$ \\
\hline The pitch angle & $\beta=0^{\circ}$ \\
\hline specific optimal speed & $\lambda_{\mathrm{pgti}}=8.1$ \\
\hline $\begin{array}{l}\text { Coefficient of maximum } \\
\text { power }\end{array}$ & $\mathrm{C}_{\mathrm{vms}}=0.48$ \\
\hline
\end{tabular}

Table 2. PMSG Parameters

\begin{tabular}{|l|l|}
\hline Rated power & $\mathrm{P}=10 \mathrm{kw}$ \\
\hline Stator resistance & $\mathrm{R}_{\mathrm{z}}=0.00829 \Omega$ \\
\hline Direct stator inductance & $\mathrm{L}_{\mathrm{d}}=0.174 \mathrm{mH}$ \\
\hline Stator inductance quadrature & $\mathrm{L}_{\mathrm{q}}=0.174 \mathrm{mH}$ \\
\hline Field flux & $\Psi_{\mathrm{d}}=0.071 \mathrm{wb}$ \\
\hline Number of pole pairs & $\mathrm{n}_{\mathrm{p}}=6$ paire pole \\
\hline
\end{tabular}

\section{REFERENCES}

[1] Oghafy, V., \& Nikkhajoei, H. (2008, July). Maximum Power Extraction For a Wind-Turbine Generator with No Wind Speed Sensor. In Power and Energy Society General Meeting-Conversion and Delivery of Electrical Energy in the 21st Century, 2008 IEEE (pp. 1-6). IEEE.

[2] Abdullah M A, Yatim A H M, Tan C W, et al.(2012) $A$ Review of Maximum Power Point Tracking Algorithms for Wind Energy Systems. Renewable and Sustainable Energy Reviews.; vol. 16, no 5, p. 3220-3227.

[3] Raza Kazmi S M, Goto Hiroki, Guo Hai-Jiao, et al(2010) Review and Critical Analysis of the Research Papers Published Till Date on Maximum Power Point Tracking in Wind Energy Conversion System. In: Energy Conversion Congress and Exposition (ECCE). IEEE; p. 4075-4082.

Joanne, H., and Alireza. B (2008) A New Adaptive Control Algorith for Maximum Power Point Tracking for Wind Energy Conversion Systems. In: Power Electronics Specialists Conference (PESC). IEEE; p. 4003-4007.

[4] Raza Kazmi S M, Goto Hiroki, Guo Hai-Jiao, et al. (2011) A Novel Algorithm for Fast and Efficient Speed-Sensorless Maximum Power Point Tracking in Wind Energy Conversion Systems. Industrial Electronics. IEEE Transactions on.; vol. 58, no 1, p. 29-36.

[5] Shravana, M., and Ginn H L. (2011) Comprehensive Review of Wind Energy Maximum Power Extraction Algorithms. In: Power and Energy Society General Meeting. IEEE,; pp. 1-8.

[6] M'Sirdi, N. K.., Nehme, B., Abarkan, M and Rabhi, A. (Nov. 2014) The Best MPPT Algorithms by VSAS Approach for Renewable Energy Sources (RES) . Int. Conference EFEA 2014, Paris. 
[7] M'Sirdi, N. K., Rabhi, A., \& Abarkan, M. (2013). A New VSAS approach for Maximum Power Tracking for Renewable Energy Sources (RES). Energy Procedia, 42, 708-717.

[8] Kelvin, T., and Syed, I. (2004) Optimum Control Strategies in Energy Conversion of PMSG Wind Turbine System Without Mechanical Sensors. Energy Conversion. IEEE Transactions on.; vol. 19, no 2, p. 392-399.

[9] LIN, Whei-Min et HONG, Chih-Ming. (2010) Intelligent Approach to Maximum Power Point Tracking Control Strategy for Variable-Speed Wind Turbine Generation System: Energy, vol. 35, no 6, p. 2440-2447.

[10] Iulian, M., Iuliana , B. A., and Nicolaos-Antonio, C., ET AL. (2008) Optimal Control of Wind Energy Systems: Towards a Global Approach. Springer..

[11] Ming ,Y., Gengyin, L. and Ming, Z., Et Al. (2007) Modeling of the Wind Turbine with a Permanent Magnet Synchronous Generator for Integration. In: Power Engineering Society General Meeting. IEEE.pp. 1-6.
[12] Monica, C. , Santiago, A. Et Juan Carlos, B. (2006) Control Of Permanent-Magnet Generators Applied to Variable-Speed Wind Energy Systems Connected to the Grid. Energy Conversion. IEEE Transactions on.; vol. 21, no 1, p. 130-135.

[13] Munteanu I, Guiraud J, Roye D, ET AL. (2006) Sliding Mode Energy-Reliability Optimization of a Variable Speed Wind Power System. In: Variable Structure Systems.. VSS'06. International Workshop on. IEEE. pp. 92-97

[14] Eftichios K. , and Kostas K. (2006) Design of a Maximum Power Tracking System for Wind-EnergyConversion Applications. Industrial Electronics. IEEE Transactions on.; vol. 53, no 2, p. 486-494.

[15] Ching-Tsai P.and Yu-Ling, J.(2010) A Novel Sensorless MPPT Controller for a High-Efficiency Microscale Wind Power Generation System. Energy Conversion. IEEE Transactions on; vol. 25, no 1, pp. 207-216. 